\title{
Effects of Different Stress Ratios on Fatigue Crack Growth of Rice Husk Fibre-reinforced Composite
}

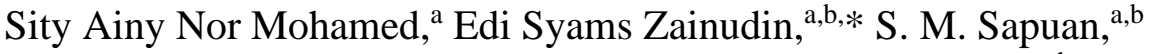
Mohd Azaman Md. Deros, ${ }^{c}$ and Ahmad Mubarak Tajul Arifin ${ }^{\mathrm{d}}$

Polymers and polymer composites are susceptible to premature failure due to formation of cracks and microcracks throughout their service. Evolution of cracks and microcracks induces catastrophic material failure. Hence, detection/diagnostics, as well as effective repair of cracks and microcracks, is essential to ascertain performance reliability, cost efficiency, and safety for polymer structures. Upon adopting the Paris relation for empirical data, this study incorporated a mathematical model after weighing in cracks initiation and propagation in rice husk $(\mathrm{RH})$ polymer structures, along with the several viable techniques for life prediction and fracture observation. The specimens contained $35 \% \mathrm{RH}$ fibres and were produced via an injection molding process. Fatigue cracks were evaluated for stresses between 80 and $90 \%$ from ultimate tensile strength (UTS) for $R=0.1,0.3$, and 0.5 . The outcomes signified that the increment in $R$ value enhanced the growth rate of the crack. Upon elaborating the fracture analysis, this study discusses in detail both fracture mechanics and formation.
\end{abstract}

Keywords: Crack growth; Fracture; Life prediction; Rice husk/polypropylene

Contact information: a: Department of Mechanical and Manufacturing Engineering, Faculty of Engineering, Universiti Putra Malaysia, 43400 UPM Serdang, Selangor Darul Ehsan, Malaysia; b: Laboratory of Biocomposite Technology, Institute of Tropical Forestry and Forest Products (INTROP), Universiti Putra Malaysia, 43400 UPM Serdang, Selangor, Malaysia; c: School of Manufacturing Engineering, Universiti Malaysia Perlis, Kampus Alam Pauh Putra, 02600 Arau, Perlis, Malaysia; $d$ : Department of Materials and Design Engineering, Faculty of Mechanical and Manufacturing Engineering, Universiti Tun Hussein Onn Malaysia, 86400 Batu Pahat, Johor, Malaysia;

* Corresponding author: edisyam@upm.edu.my

\section{INTRODUCTION}

Over the recent years, reinforcing polymers with natural fibres have been highly sought, particularly when exceptional mechanical properties can be obtained at relatively low cost. Natural fibre-reinforced thermoplastics are light in weight, have adequate strength and stiffness, are low in cost, and can be easily produced via conventional plastics processing techniques. The use of natural fibres as an alternative to synthetic fibres is driven by ecological reasons, apart from their vast benefits. Natural fibres are low in cost and density, highly available and renewable, biodegradable, possess specific properties, and are less abrasive to processing equipment (Pickering et al. 2016). Nevertheless, the potential use of natural fibres as reinforcement is affected due to their incompatibility with hydrophobic polymer matrix.

Among short-fibre-reinforced plastics (SFRP) for natural fibre, rice husk (RH) is a major agricultural residue that has been extensively used as a filler material. The potential of $\mathrm{RH}$ as fibre is huge, mainly due to its resistance to decomposition in the ground, difficult 
digestion, and low nutritional value for animals. According to Marti-Ferrer, the lignin and hemicellulose contents of RH are lower than those of wood, despite the fact that they share similar cellulose content. For this reason, $\mathrm{RH}$ can be processed at higher temperatures than wood (Bisht and Gope 2015). The RH has garnered much attention in manufacturing polymer composites.

Polypropylene (PP) is a useful commodity polymer matrix with outstanding properties, such as low density, good surface hardness, excellent abrasion resistance, as well as exceptional mechanical and barrier properties to water. It is also low in cost, has worldwide production, has non-intricate processing, is capable of burning without producing toxic emissions, and is recyclable (Abdelhaleem et al. 2018). Natural fibrereinforced PP composites have been commonly applied in the automotive and building industries, particularly in structural applications, such as fencing, decking, outdoor furniture, window parts, roofline product, doors, and panels. The injection molding process produces SFRP components at higher rates in an economical manner. This has led the production of fatigue-sensitive components to escalate steadily across numerous industries.

Fatigue in SFRP refers to degradation of material properties that occurs when the material experiences cyclic loading, thus causing damage and cracks in the material. These SFRP composites are designed to minimise the impact of fatigue failure, despite being subjected to fatigue loadings (Zakaria et al. 2016). One reason among others is mainly that the failure of these composites takes place suddenly and without prior notice, thus the importance of comprehending and predicting fatigue life. The propagation behaviour of fatigue cracks in SFRP is highly anisotropic, as it depends on the fibre orientation generated by injection molding (Tanaka et al. 2014). For these applications, apart from high stiffness and mechanical strength, adequate fracture toughness is often required. Although significant efforts have been devoted to mechanical and fracture attributes of PP, along with their blends and composites, many aspects of these remain unclear. Hence, further investigation is required to apply these materials in structural applications.

In relation to fracture behaviour, two parameters are commonly observed, namely the stress intensity factor (SIF) and the energy release rate of the strain (SERR). In fracture mechanics, SIF is one of the main inherent and functional parameters defined by George R Irwin (1957) (Soman et al. 2018). In crack content, the load at the tip of the crack is measured by SIF, which is associated with distribution of crack and structural failure. Meanwhile, SERR, which explains fracture strength, is defined by Griffith as energy dissipated during fracture per unit (Karr and Akcay 2016). When the structure is loaded, the crack propagates and creates a new cracking surface, which denotes strain energy. The first element is related to the acceptance criteria of the parameter that defines similitude. It is noteworthy that data can be mischaracterised if the similitude parameter is not well defined (Yao et al. 2014).

In this study, PP/RH composites with constant fibre content were prepared. The effect of various loadings on the crack growth rate was investigated via the SERR approach. The failure mechanisms that occurred in the composites were identified. In brief, the objective of this study was to retrieve reliable fatigue crack growth data that are beneficial for design purposes, as well as to correlate morphology with fracture behaviour displayed by the material. The findings showed that a higher load ratio resulted in a slower dis-bond growth rate. The knowledge of structure-property correlation in these materials is critical towards tailoring the required mechanical properties of the end-product. 


\section{THEORETICAL BACKGROUND}

\section{Fatigue Crack Growth in SFRPs}

Cracks are an important feature of fatigue failure. The main cause of fatigue failure starts with the initiation and the propagation of crack to reach a critical length, whereby the remaining material fails to withstand the load. Generally, a component that fails fatigue undergoes three fatigue stages: the beginning of the crack, the crack growth stage, and the final fracture (Wong et al. 2010). The final stage of the fatigue process is when parts of the component or structure of the material are broken and split into two or more pieces (HojjatiTalemi et al. 2015). During the fatigue process, the load experienced by the material is lower than the material strength. When the load value exceeds the threshold, the material fails despite being under the value of static load that would lead to failure. The load that causes fatigue failure is referred as cyclic load, but naturally, the load encountered by a material is always not uniform. The fatigue process occurs when the applied load exceeds a certain value called the fatigue limit (Barbosa et al. 2019).

Composite materials are inhomogeneous and anisotropic (Mortazavian and Fatemi 2015; Tanaka et al. 2015), whereby their behaviour is more intricate than that of homogeneous and isotropic materials, such as metals. The main reasons for this are that the varied types of damages that can occur, such as fibre fracture, matrix cracking, matrix crazing, fibre buckling, fibre-matrix interface failure, and delamination (Jollivet et al. 2013), which strongly affect their varying growth rates. In order to address this problem, vast empirical and numerical studies have been performed in the past decades. These studies can be explicitly classified into four categories: stress/strain-based methods, fracture mechanics-based methods, cohesive zone models, and extended finite elementbased methods. Among them, the fracture mechanics-based methods have been widely applied to characterise the fatigue growth behaviour by correlating fatigue crack growth with fracture mechanics concept, such as SIF and SERR (Jones et al. 2013).

The Paris relation is one of the most outstanding achievements in fatigue crack growth study domain in both metals and composites. To date, this relation and its variations are not only employed in scientific research, but also in engineering design. It is worth highlighting that people indeed prefer selecting SERR as the similitude parameter in fatigue crack growth analysis of composite materials, instead of SIF, which is commonly applied in metals. This is mainly due to the difficulty in SIF calculation of inhomogeneous and anisotropic materials, as well as the equivalence relationship between SERR and SIF.

\section{Paris-based Concept and Correlation}

For inhomogeneous structure in the presence of short fibres, fatigue-crack propagation in SFRP composites tend to adhere to the Paris crack-propagation equation. A widely utilised approach is to apply the linear elastic fracture mechanics (LEFM) using SERR $(G)$ in an analogous manner (Khan et al. 2014) to metal crack growth in terms of SIF $(K)$. The primary reason to employ $G$ and not $K$ is because the local crack tip stress field used to determine $K$ is difficult to obtain in inhomogeneous composite laminates. Although solutions are available for $K$ for interfacial cracks in layered orthotropic materials, these solutions can result in oscillatory singularities and complex $K$ solutions with real and imaginary components that further complicate LEFM analysis. Hence, the application of $G$ hinders these issues. The relationship can be expressed as, 


$$
\frac{d a}{d N}=C \Delta K^{n} \quad \text { or } \quad \frac{d a}{d N}=C \Delta G^{n} \quad \frac{d a}{d N}=C G_{\max }^{n} \text { or } \frac{d a}{d N}=C \Delta \sqrt{G}^{n}
$$

where $\mathrm{d} a / \mathrm{d} N$ is crack growth rate ( $\mathrm{mm} /$ cycle), $\Delta K$ denotes SIF range (MPa $\sqrt{\mathrm{m}}), G$ signifies SERR (N/mm or $\mathrm{mJ} / \mathrm{mm}^{2}$ ), while $C$ and $n$ are curve fitting parameters, in which each must have physical meaning. The dimensional analysis highlights that constant $C$ has units that serve as exponent value $n$, which obscures the physical meaning of $C$ (Alderliesten et al. 2018). The SIF can be calculated using the following equations,

$$
\begin{aligned}
& \Delta K=\frac{\Delta P}{B W^{\frac{1}{2}}} f(\alpha) \\
& f(\alpha)=\frac{2+\alpha}{(1-\alpha)^{3 / 2}}\left(0.866+4.64 \alpha-13.32 \alpha^{2}+14.72 \alpha^{3}-5.6 \alpha^{4}\right) \\
& \alpha=\frac{a}{W} \\
& G=\frac{K^{2}}{E}
\end{aligned}
$$

where $\Delta P$ is load range, $B$ refers to specimen thickness $(\mathrm{mm}), W$ denotes specimen width (mm), $a$ represents crack length (mm) (Boonyapookana et al. 2011), and $E$ is elastic modulus (MPa). Hence, SERR becomes,

$$
\Delta G=(\Delta P)^{2} \frac{G_{\max }}{P_{\max }^{2}}
$$

where $P_{\max }$ represents the maximum applied force $(\mathrm{N})$ in fatigue cycle, and $\Delta P$ depicts the range of applied load in fatigue cycle.

In discussing these models, Rans et al. (2011) asserted that when taking $G_{\max }$ or $\Delta G$ $=\left(G_{\max }-G_{\min }\right)$ as the similitude parameter, the stress ratio effect on the crack growth resistance curves becomes contrary to that commonly observed for metals when plotting crack growth rate against $\Delta K=\left(K_{\max }-K_{\min }\right)$. The parameter $\Delta G$ has been widely used as a crack driving force $(\mathrm{CDF})$ to characterise the delamination growth rate in FRP composite structures. However, it was found that for the same value of $\Delta G$, the $d a / d N$ versus $\Delta G$ curves suggest that increment in mean stress can result in slower delamination growth rate. For constant $\Delta G$, the value of $d a / d N$ should be high for higher $R$-ratio (or load ratio) in cyclic fatigue test, mainly because the mean stress increases with increment of $R$-ratio. Moreover, increment of $R$-ratio for a given value of $\Delta G$ decreased $d a / d N$. This anomaly raises the question if $\Delta G$ is a valid $C D F$.

Fortunately, when expressing $d a / d N$ as a function of $\Delta G^{\prime}$ in Eq. 8 or $\Delta \sqrt{G}$ in Eq. 9, this anomaly did not occur. In fact, these two terms are directly related (Hu et al. 2016). Using Eq. 7, the results showed that these approaches are capable of eliminating the anomaly that arises from using $\Delta G$ as the CDF in SFRP composite structures, as observed for metals, mainly due to the correlation between $G$ and $K^{2}$ in Eq. 5. Next, Paris relationship was performed to identify the substance behaviour on the basis of any 
resemblance. Research findings from the literature were used to explain this notion. As a result, it was found that the parameters in Eq. 10 depended on the cyclic load set, which reduced the existing mean load effect when using Eq. 6. Although various bases of similarity may be chosen to explain the processes of fracturing, it is useful to separate such processes on the basis of cyclic (Eq. 10) and monotonous loading (Eq. 6) results. Gradually, the selection of an independent variable to fit the data becomes random when Paris model is used to match the experimental outcomes. It is merely an exercise to interpret experimental results. Further relationships and definitions involving these functions are provided in Eqs. 7 through 10:

$$
\begin{aligned}
& \Delta \sqrt{G}=\sqrt{G_{\max }}-\sqrt{G_{\min }} \\
& \Delta G^{\prime}=(1-R)^{2} G \\
& \Delta \sqrt{G}=(1-R) \sqrt{G} \\
& \Delta G^{\prime}=(\Delta \sqrt{G})^{2}
\end{aligned}
$$

These equations are presented by using linear superposition, hence signifying that the parameter depends on the cyclic load range. This means that the mean load dependency is dismissed upon applying $\Delta G$. Finally, adopting the Paris relation to correlate with empirical data selection for fitting can be performed in a non-arbitrary manner to obtain curve fit, although this exercise is an attempt to capture the material behaviour based on some similitude bases. In fracture mechanism, it is indeed convenient to understand these mechanisms based on cyclic loading effects.

\section{METHODOLOGY}

In this study, RH/PP composites pallets were prepared in SIRIM Green Laboratory, Shah Alam. Experimental Ground RH was dried at $105^{\circ} \mathrm{C}$ in an air dryer oven for $24 \mathrm{~h}$ to expel any moisture trapped to a content of 1 to $2 \%$, and then the material was stored over desiccant in a sealed container. The RH was then mixed with PP using a tumbler mixer to obtain better dispersion of RH and PP. Later, the mixed compounds were melt-blended using twin screw extruder Betol BTS 40 (Asset Exchange, Chicago) at temperature profiles of $160{ }^{\circ} \mathrm{C}$ to $190{ }^{\circ} \mathrm{C}$ from feed zone to die zone, respectively. The twin screw extruder has $33 \mathrm{~L} / \mathrm{D}$ and is a co-rotating type. Using $100 \mathrm{rpm}$ of screw speed, the compounds were extruded and pelletised. These pellets were stored in a sealed container and dried for about 3-4 hours before being injection molded.

Figure 1 illustrates the test specimen of this study that adhered to ASTM E-64713a (2014). The crack length lines were drawn $2 \mathrm{~mm}$ apart from each other along the total $18 \mathrm{~mm}$ crack propagation direction. These lines served as reference to capture adequate life cycles. The composite material was fabricated via injection molding process using 60tonne Haitian MA600 II/130 molding machine (Absolute Machinery, Southgate Street, Worchester), as displayed in Fig. 2. The composite materials were composed of $35 \% \mathrm{RH}$ consistently as reinforcement and PP as matrix. The test specimens were subjected to tensile test and constant amplitude fatigue tests. The tensile test was performed in 
accordance with ASTM D638-10 (2010). The test was operated at a constant head-speed of $5 \mathrm{~min} / \mathrm{mm}$.

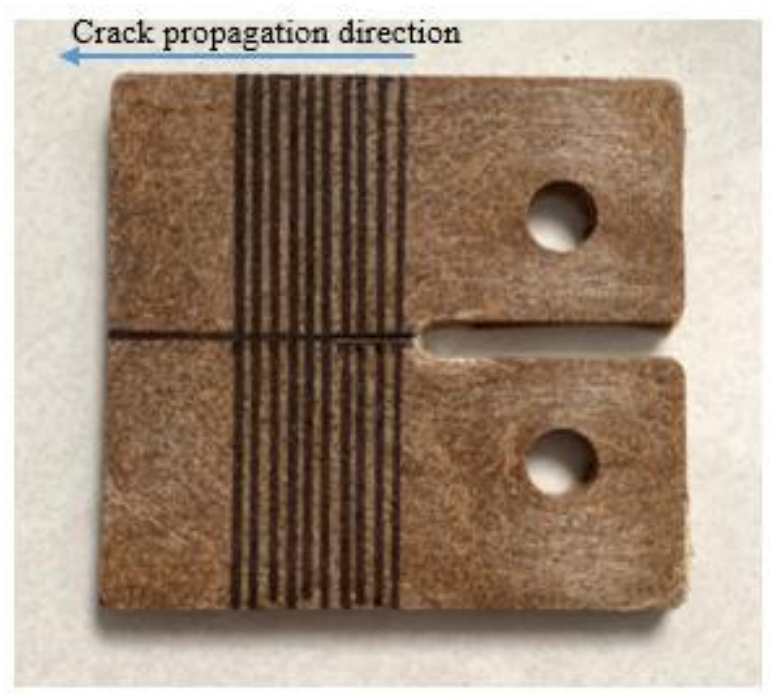

Fig. 1. Test specimen

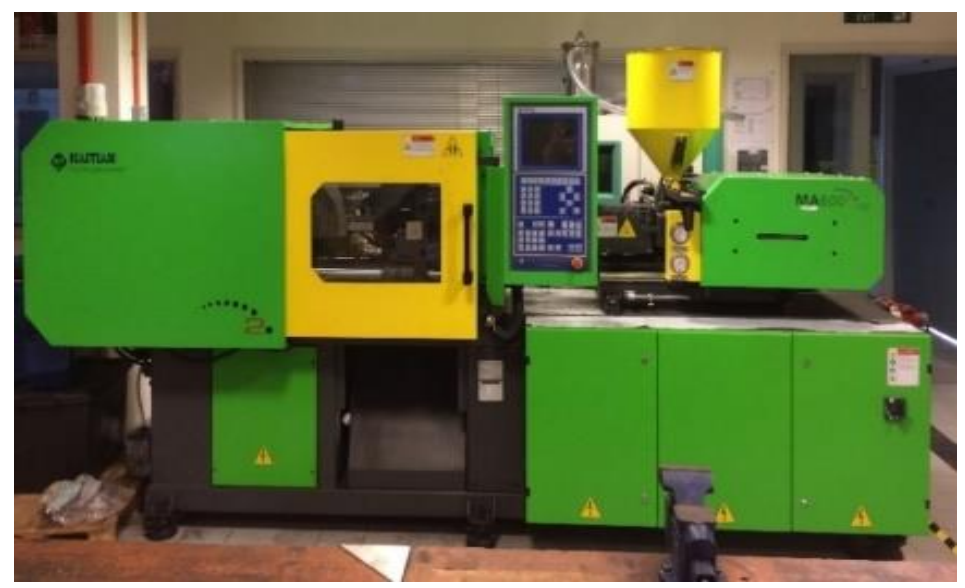

Fig. 2. 60-tonne injection molding machine

After obtaining the mechanical properties, a fatigue test was carried out in accordance with ASTM E-647-13a (2014). Fatigue crack propagation tests were performed with a tension-tension mode on Servopulser EHF-E, Shimadzu (Shimadzu Corporation, Kyoto, Japan) test machine (Fig. 3). Fatigue testing was performed at room temperature, as well as under load-controlled conditions. Constant amplitude loading using sine wave at $3.0 \mathrm{~Hz}$ and stress ratios at $R=0.1,0.3$, and 0.5 was utilised. The load was obtained as percentage from the value of UTS, which ranged from 80 to $90 \%$. For each stress ratio, the test was repeated for five specimens, and the average values were determined after each test.

Fractography testing was performed on the specimens using Phenom ProX, Thermo Fisher Scientific (Waltham, MA, USA) scanning electron microscope (SEM) machine (Fig. 4) after completing the fatigue test. Fractography was performed to identify the surface structure of the specimen. Figure 5 illustrates the arrangement of the specimen. 
Fractography observation on matrix and reinforcement failure was made using the micrograph image.

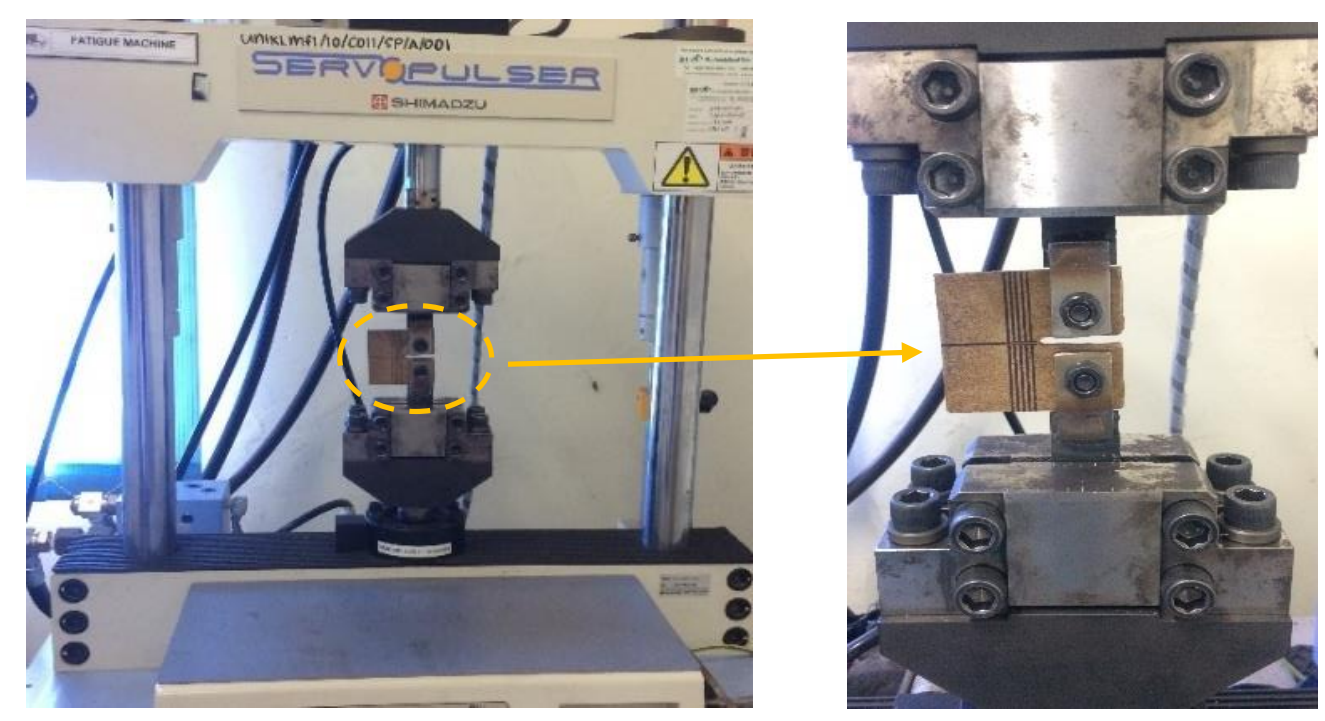

Fig. 3. Fatigue crack test under tension-tension mode

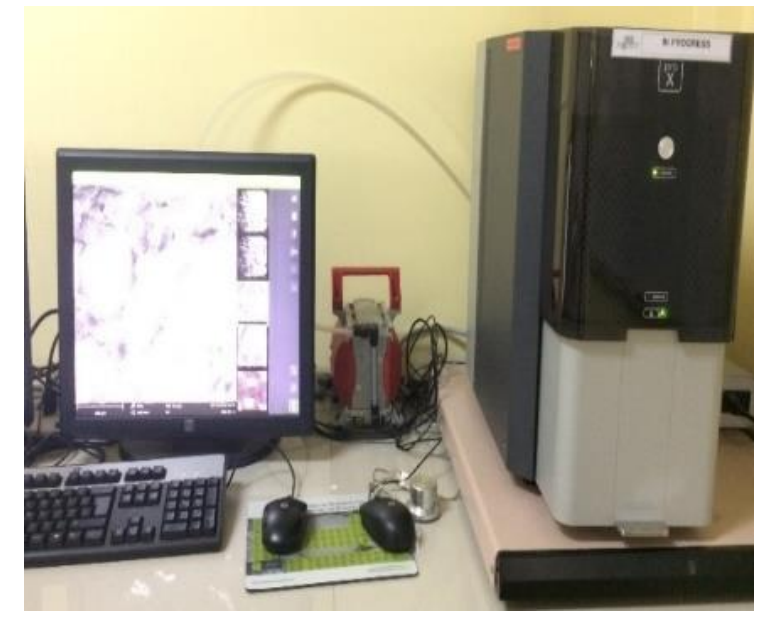

Fig. 4. Phenom $X$ Prodesktop SEM

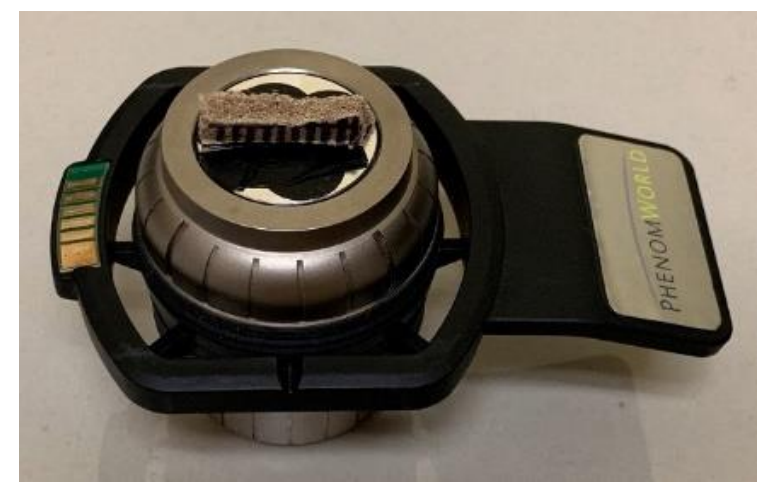

Fig. 5. Arrangement of specimen on the sample holder 


\section{RESULTS AND DISCUSSION}

Figures 6 through 8 illustrate graphs of the crack length, $a$, against the number of cycles, $N$, for three stress ratios $(R=0.1,0.3$, and 0.5$)$ for specified loads: $S_{80}, S_{85}$, and $S_{90}$. The figures display that the number of end cycles increased as the value of the stress ratio increased. With increasing stress ratio, there was a decrease in the value of amplitude stress experienced by the specimen. The empirical data revealed that under any given loading condition, the rate of crack growth was small and it changed slowly for most of the loading cycles. Then it rapidly increased with increasing crack length prior to fracture. In the final part of fatigue failure, the crack propagation rates were extremely high.

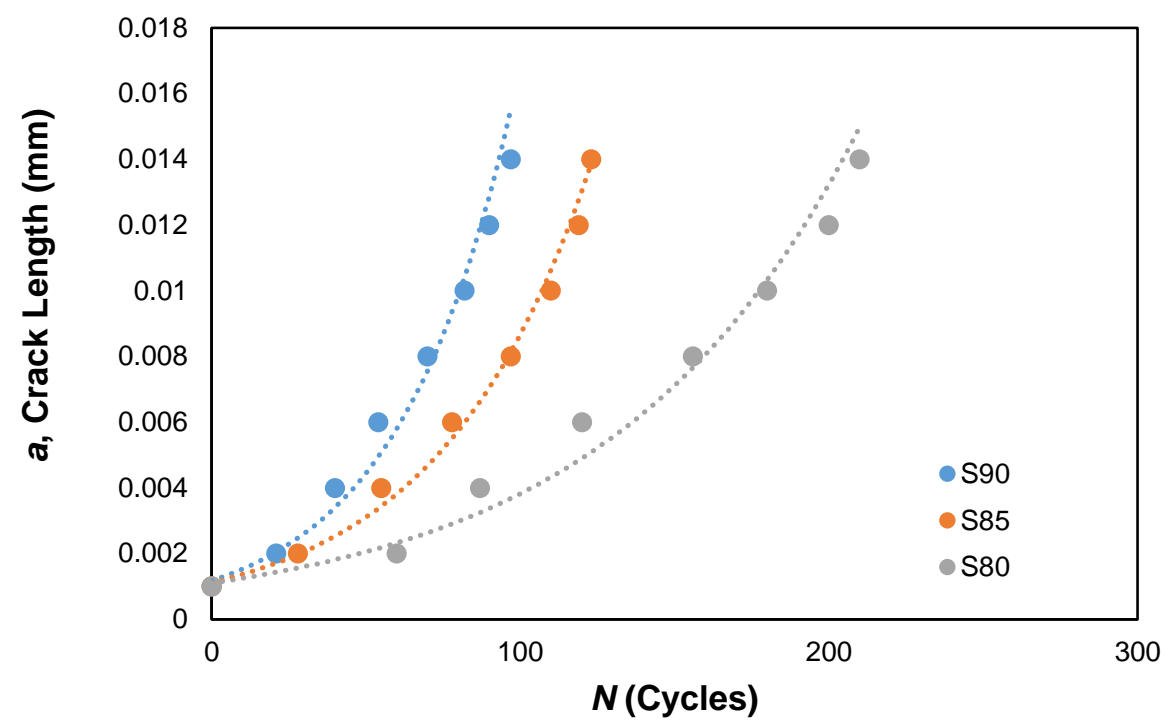

Fig. 6. Different crack lengths for $S_{80}, S_{85}$, and $S_{90}$ at $R=0.1$

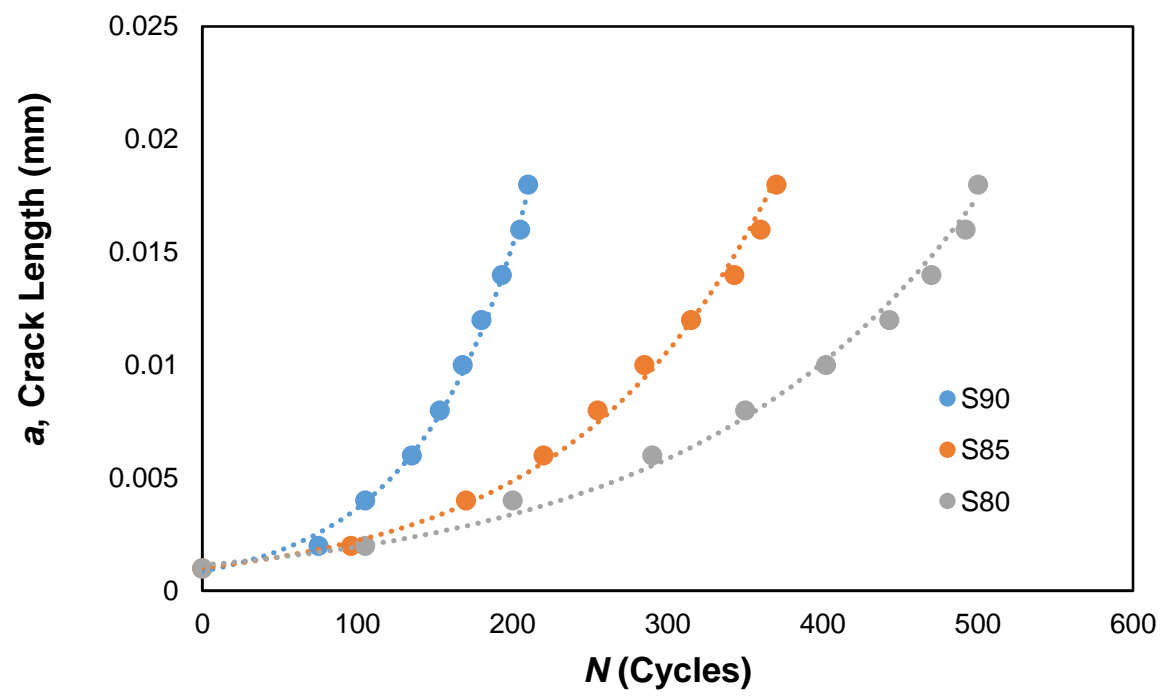

Fig. 7. Different crack lengths for $S_{80}, S_{85}$, and $S_{90}$ at $R=0.3$ 


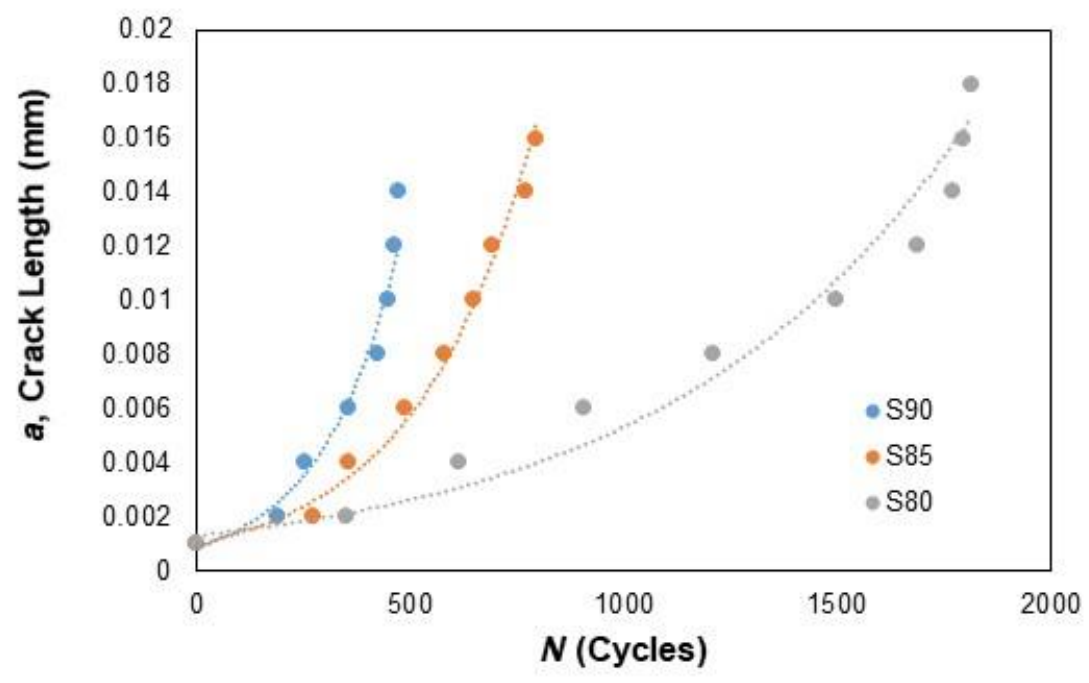

Fig. 8. Different crack lengths for $S_{80}, S_{85}$, and $S_{90}$ at $R=0.5$

The log-log plots of crack propagation rate $d a / d N$ versus SERR range $\Delta \sqrt{G}$ are portrayed in Fig. 9. Based on the Paris-based approach, the mathematical relation was formed by the straight line drawn on each graph in Fig. 9. The coefficient of determination, $R^{2}$, for the straight line is presented in each figure using Microsoft Excel. In this study, $R^{2}$ refers to the statistical measurement of the extent of data derived from the regression line, in which this value is often used to evaluate the acceptability of a regression model. Sivák and Ostertagová (2012) asserted that while $R^{2}$ values always range between 0 and $1, R^{2}$ values that exceed 0.85 indicate exceptional regression model. This equation is presented in Table 1. It seemed that the $R^{2}$ values did exceed 0.85 for all stress ratio values. This signifies that the correlation between $\log d a / d N$ and $\log \Delta \sqrt{G}$ is good and acceptable.

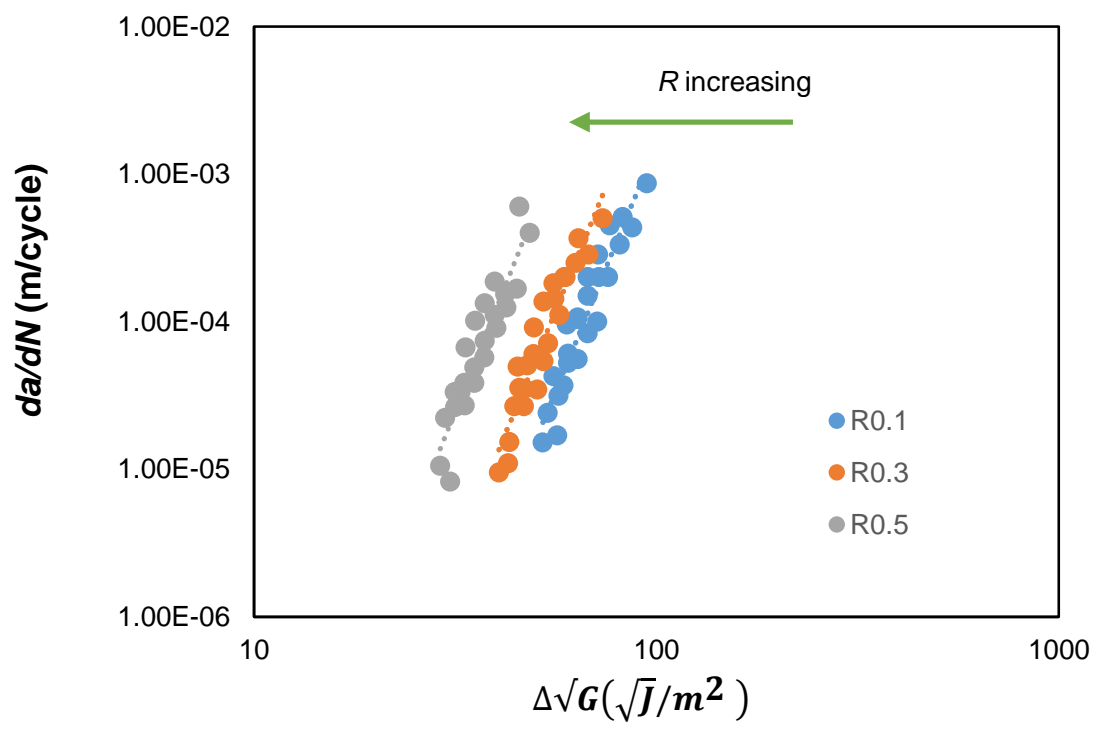

Fig. 9. Crack propagation rate da/dN vs SERR range for different load ratios 
Table 1. The Mathematical Model of Paris Law at Different Stress Ratios

\begin{tabular}{|c|l|c|}
\hline Stress Ratio $R$ & Paris Law & $R^{2}$ \\
\hline 0.1 & $\frac{d a}{d N}=\left(7 X 10^{-17}\right)(\Delta \sqrt{G})^{6.6657}$ & 0.8909 \\
\hline 0.3 & $\frac{d a}{d N}=\left(2 X 10^{-16}\right)(\Delta \sqrt{G})^{6.7076}$ & 0.8949 \\
\hline 0.5 & $\frac{d a}{d N}=\left(1 X 10^{-15}\right)(\Delta \sqrt{G})^{6.8303}$ & 0.8524 \\
\hline
\end{tabular}

Based on this graph, the SERR range $\Delta \sqrt{G}$ is a better parameter than the SIF range $\Delta K$. This is because $\Delta \sqrt{G}$ incorporates the effect of load ratio. Parameters $C$ and $n$ were determined from the fitting test data. For each given load ratio, $R$, constants $C$ and $n$ (for $d a / d N$ in $\mathrm{m} /$ cycle and $\Delta \sqrt{G}$ in $\sqrt{J} / \mathrm{m}^{2}$ ) are listed in Table 2, which indicated that both $C$ and $n$ increased with increment of load ratio, $R$. This unravels the strong impact of load ratio, $R$, on crack propagation rate, $d a / d N$. The crack propagation rate, da/dN, seemed to increase with increasing load ratio, $R$. The higher the load ratio, the slower was the disbond growth. This is because the cyclic load range at higher load ratio was smaller. This led to a slower dis-bond growth rate. Therefore, the outcomes violated the fact that fatigue resistance is higher at high stress ratio, especially when compared to that at a low stress ratio, when using $\Delta \sqrt{G}$ as similitude to interpret fatigue crack growth (Yao et al. 2015).

Table 2. Material Constants $C$ and $n$ for the Three Load Ratios

\begin{tabular}{|c|c|c|}
\hline Stress Ratio $R$ & $C$ & $n$ \\
\hline 0.1 & $7.0 \times 10^{-17}$ & 6.6657 \\
\hline 0.3 & $2.0 \times 10^{-16}$ & 6.7076 \\
\hline 0.5 & $1.0 \times 10^{-15}$ & 6.8303 \\
\hline
\end{tabular}

Cracks in composites are more complicated in nature than those in homogenous materials. The failure mechanism in a fibre-reinforced composite is composed of debonding of fibre-matrix interface, matrix fracture, fibre de-bonding, stress redistribution, fibre fracture, and fibre pull out (Naebe et al. 2016). For this composite, the failure mechanisms did not operate simultaneously, and no specific mechanism dominated the fracture attribute. Nevertheless, the damage process seemed to be always driven by the same mechanism: the first damage demanded low energy consumption (interface or matrix failure), while the last stage (fibre breakage) required more significant energy level.

The first step of damage started in zones of lower strength, such as the matrix-fibre interfaces and the matrix itself. Instances of matrix damage were mainly noted in areas where the fibres were disoriented in the load axis, especially when the strain in the matrix broke. Finally, when the volume ratio of the matrix damage hit a certain level, the final stage of damage corresponded to the failure of fibres. Such damage is commonly noted in the final stages of ruin in areas where fibre orientation coincides with stress axis. Matrix damage is inclusive of fracture of fibre-matrix interfaces and fracture within the matrix. Figure 10 portrays the fracture types that denote fatigue striations. Striations are often localised and can be difficult to discover. The gradual deterioration of a fibre-reinforced 
composite, along with loss of stiffness in damaged zones, leads to continuous redistribution of stress that decreases the stress concentrations within the structure.

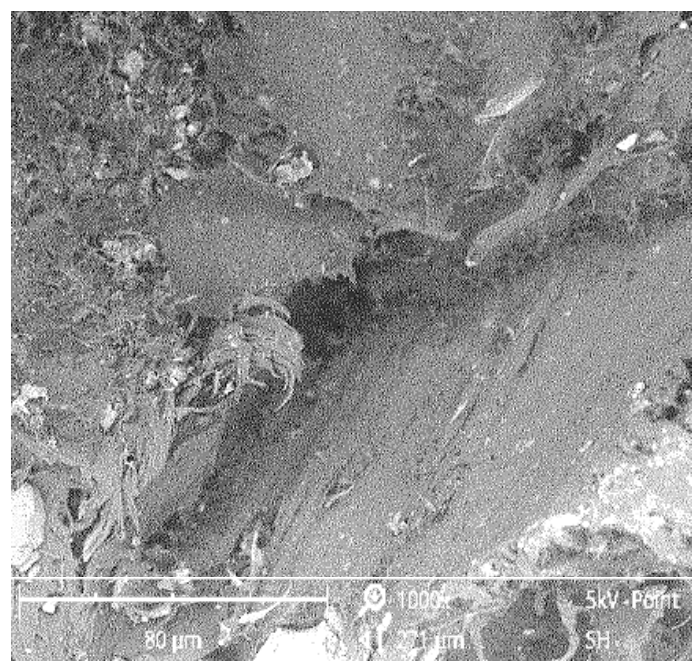

Fig. 10. Striations mark at the matrix interfaces due to fatigue
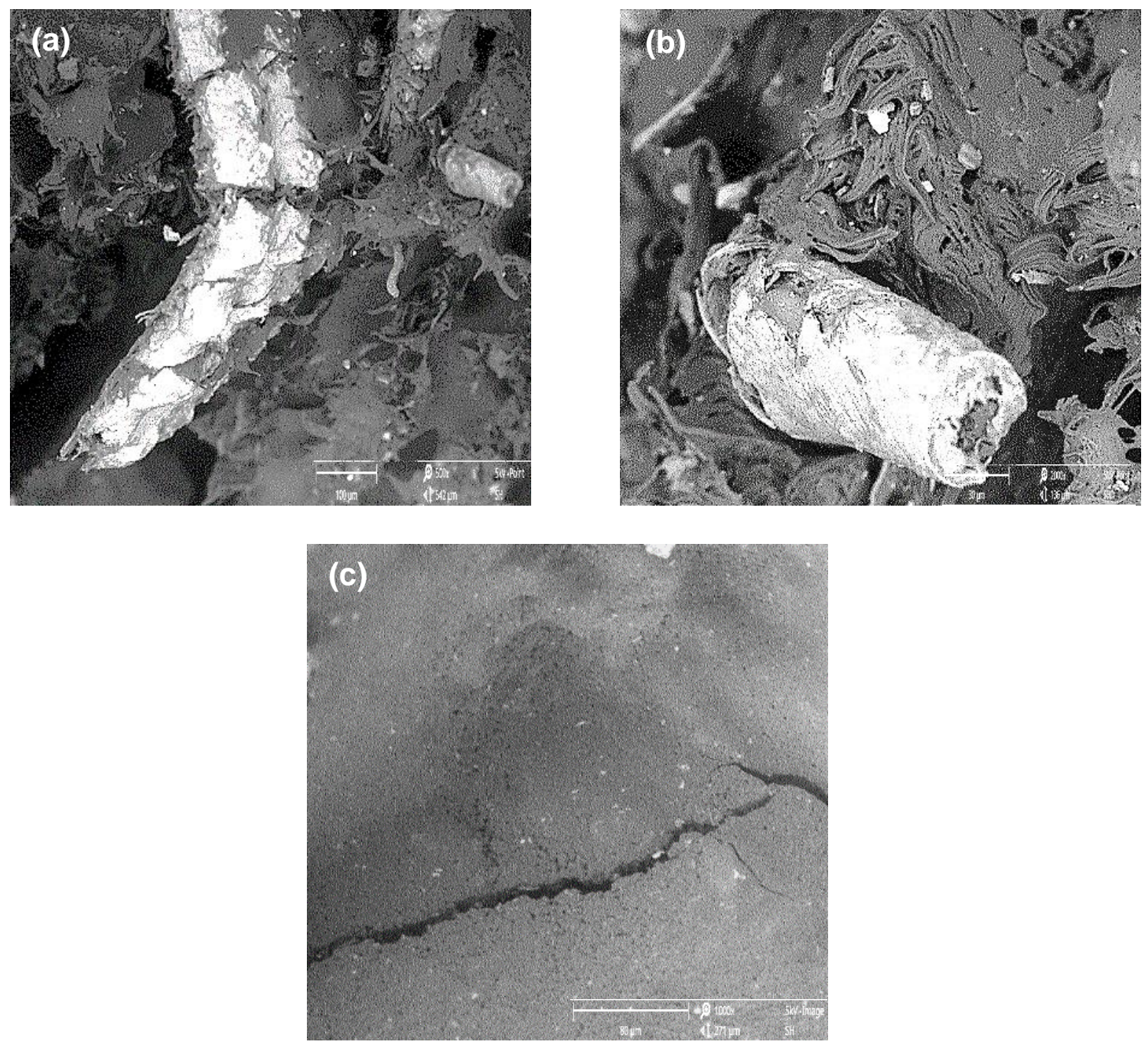

Fig. 11. Different damages to final fracture: (a) fibre break, (b) fibre pull-out, and (c) matrix crack 
The second stage occurs when de-bonding is initiated from the distributed fibre breaks and propagation. When a weak element of an intact fibre becomes overloaded, it may fail and give rise to new de-bonding. In this case, fibre breaks accumulate, and the material will eventually fail. Turning to this study, matrix fibres that were broken close to the crack could be pulled out (Fig. 11) as the crack opened, thus decreasing the aspect of stiffness in the fibres. The further the fibres were pulled out, the lower was the stress in the fibre bonding. The pull out could be due to the interfacial de-bonding and followed by frictional sliding or shear yielding of the matrix material close to the fibre, which depended on interfacial strength (Kaminski et al. 2015). The large poor-bonded interfacial region between fibre and matrix polymer caused brittle deformation of the composite, as observed in the SEM micrographs.

\section{CONCLUSION}

Polymer composites, which are subjected to synergistic effects of mechanical loading and environmental exposure, are usually more susceptible to microcrack formation and propagation. Therefore, microcracks may be formed during static, dynamic, and fatigue cyclic loading. Based on the outcomes retrieved from this study, the following conclusions have been drawn:

1. Microcracking in polymer composites inevitably leads to degradation of mechanical properties and acts as an initiator for other types of damage, whereby the interfacial debonding of the fibre matrix eventually causes fracture in the fibre. As a consequence, microcracks potentially contribute to total material deterioration and impair the longterm stability of polymer composite materials. Detection and predictive measurement of cracks and microcracks were notable for preventive and corrective actions in polymer composites. Thus, the Paris relationship was developed to characterise the effect of stress ratio on the polymer composite crack growth assessment method, including crack initiation and propagation. Upon increasing the stress ratio from 0.1 to 0.5 , the constant values for $C$ and $n$ for the material increased respectively in a range of $7.0 \times 10^{-17}$ to $1.0 \times 10^{-15}$ for $C$, whereas for parameter $n$, the value increased from 6.6 to 6.8 .

2. The empirical data signified that fatigue fracture was significantly stress ratio dependent. At similar stress ratio, fatigue resistance appeared identical. Nonetheless, fatigue resistance increased with increment of stress ratio, while material constant displayed increment in its value. The resistance dependence on stress ratio is the physical reason for the impact of stress ratio on fatigue crack growth.

3. The mechanisms related to this dependence were investigated via SEM fractography in this study. For a given fibre-reinforced composite, where the fibre was gripped by polymer matrix, the matrix crack was halted by fibre. Upon increasing the load, the crack began to pass around the fibre without breaking the interfacial bond. Interfacial shearing and lateral contraction of the fibre resulted in de-bonding and further increment of crack extension. After considerable de-bonding, the fibres broke at some weak points within the matrix, in which further crack extension was noted. The total failure of the composite occurred when the end of the broken fibre was pulled out against the frictional grip of the matrix. 


\section{ACKNOWLEDGMENTS}

The present work is supported by research grant UPM/700-2/1/GPIPS/2017/9538700 and the Malaysian Ministry of Higher Education (MyBrain15).

\section{REFERENCES CITED}

Abdelhaleem, A. M., Megahed, M., and Saber, D. (2018). "Fatigue behaviour of pure polypropylene and recycled polypropylene reinforced with short glass fiber," Journal of Composite Materials 52(12), 1633-1640. DOI: 10.1177/0021998317729888

Alderliesten, R. C., Brunner, A. J., and Pascoe, J. A. (2018). "Cyclic fatigue fracture of composites: What has testing revealed about the physics of the processes so far," Engineering Fracture Mechanics 203, 186-196. DOI:

10.1016/j.engfracmech.2018.06.023

ASTM D638-10 (2010). "Standard test method for tensile properties of plastics," ASTM International, West Conshohocken, PA, USA.

ASTM E647-13a (2014). "Standard test method for measurement of fatigue crack growth rates," ASTM International, West Conshohocken, PA, USA.

Barbosa, J. F., Correia, J. A., Freire Junior, R. C. S., Zhu, S. P. and De Jesus, A. M. (2019). "Probabilistic SN fields based on statistical distributions applied to metallic and composite materials: State of the art," Advances in Mechanical Engineering 11(8), 1-22. DOI: 10.1177/1687814019870395

Bisht, N., and Gope, P. C. (2015). "Mechanical properties of rice husk flour reinforced epoxy bio-composite," International Journal of Engineering Research and Applications 5(6), 123-128. DOI: 10.13140/RG.2.1.3457.0323

Boonyapookana, A., Nagata, K., and Mutoh, Y. (2011). "Fatigue crack growth behaviour of silica particulate reinforced epoxy resin composite," Composites Science and Technology 71(8), 1124-1131. DOI: 10.1016/j.compscitech.2011.02.015

Hojjati-Talemi, R., Zahedi, A., and De Baets, P. (2015). "Fretting fatigue failure mechanism of automotive shock absorber valve," International Journal of Fatigue 73, 58-65. DOI: 10.1016/j.ijfatigue.2014.11.010

$\mathrm{Hu}$, W., Jones, R., and Kinloch, A. J. (2016). "Discussion of the stress ratio effect on the fatigue delamination growth characterization in FRP composite structures," Procedia Structural Integrity 2, 66-71. DOI: 10.1016/j.prostr.2016.06.009

Jollivet, T., Peyrac, C., and Lefebvre, F. (2013). "Damage of composite materials," Procedia Engineering 66, 746-758. DOI: 10.1016/j.proeng.2013.12.128

Jones, R., Pitt, S., Hui, D., and Brunner, A. (2013). "Fatigue crack growth in nanocomposites," Composite Structures 99, 375-379. DOI:

10.1016/j.compstruct.2012.09.050

Kaminski, M., Laurin, F., Maire, J. F., Rakotoarisoa, C., and Hémon, E. (2015). "Fatigue damage modeling of composite structures: The ONERA viewpoint," Journal AerospaceLab 2015(9), 1-12. DOI: 10.12762/2015.AL09-06

Karr, D.G. and Akçay, F.A. (2016). "A criterion for ductile fracture based on continuum modeling of energy release rates," International Journal of Fracture 197(2), 201-212. 10.1007/s10704-016-0079-9

Khan, R., Alderliesten, R., Yao, L., and Benedictus, R. (2014). "Crack closure and fibre bridging during delamination growth in carbon fibre/epoxy laminates under mode I 
fatigue loading," Composites Part A: Applied Science and Manufacturing 67, 201211. DOI: 10.1016/j.compositesa.2014.08.028

Mortazavian, S., and Fatemi, A. (2015). "Effects of fiber orientation and anisotropy on tensile strength and elastic modulus of short fiber reinforced polymer composites," Composites Part B: Engineering 72, 116-129. DOI:

10.1016/j.compositesb.2014.11.041

Naebe, M., Abolhasani, M. M., Khayyam, H., Amini, A., and Fox, B. (2016). "Crack damage in polymers and composites: A review," Polymer Reviews 56(1), 31-69. DOI: 10.1080/15583724.2015.1078352

Pickering, K. L., Efendy, M. A., and Le, T. M. (2016). "A review of recent developments in natural fibre composites and their mechanical performance," Composites Part A: Applied Science and Manufacturing 83, 98-112. DOI: 10.1016/j.compositesa.2015.08.038

Rans, C., Alderliesten, R., and Benedictus, R. (2011). "Misinterpreting the results: How similitude can improve our understanding of fatigue delamination growth," Composites Science and Technology 71(2), 230-238. DOI: 10.1016/j.compscitech.2010.11.010

Sivák, P., and Ostertagová, E. (2012). "Evaluation of fatigue tests by means of mathematical statistics," Procedia Engineering 48, 636-642. DOI: 10.1016/j.proeng.2012.09.564

Soman, S., Murthy, K. and Robi, P. (2018). "A simple technique for estimation of mixed mode (I/II) stress intensity factors," Journal of Mechanics of Materials and Structures 13(2), 141-154. 10.2140/jomms.2018.13.141

Tanaka, K., Kitano, T., and Egami, N. (2014). "Effect of fiber orientation on fatigue crack propagation in short-fiber reinforced plastics," Engineering Fracture Mechanics 123, 44-58. DOI: 10.1016/j.engfracmech.2014.03.019

Tanaka, K., Oharada, K., Yamada, D., and Shimizu, K. (2015). "Fatigue crack propagation in short-fiber reinforced plastics," Frattura ed Integrita Strutturale 9(34), 309-317. DOI: 10.3221/IGF-ESIS.34.33

Wong, K. J., Zahi, S., Low, K. O., and Lim, C. C. (2010). "Fracture characterisation of short bamboo fibre reinforced polyester composites," Materials \& Design 31(9), 4147-4154. DOI: 10.1016/j.matdes.2010.04.029

Yao, L., Alderliesten, R.C., Zhao, M. and Benedictus, R. (2014). "Discussion on the use of the strain energy release rate for fatigue delamination characterization,"

Composites Part A: Applied Science and Manufacturing 66, 65-72. 10.1016/j.compositesa.2014.06.018

Yao, L., Alderliesten, R. C., and Benedictus, R. (2015). "Interpreting the stress ratio effect on delamination growth in composite laminates using the concept of fatigue fracture toughness," Composites Part A: Applied Science and Manufacturing 78, 135142. DOI: 10.1016/j.compositesa.2015.08.005

Zakaria, K. A., Jimit, R. H., Ramli, S. N. R., Abdul Aziz, A., Bapokutty, O., and Ali, M. B. (2016). "Study on fatigue life and fracture behaviour of fibreglass reinforced composites," Journal of Mechanical Engineering and Sciences (JMES) 10(3), 23002310. DOI: 10.15282/jmes.10.3.2016.8.0214

Article submitted: March 24, 2020; Peer review completed: May 16, 2020; Revised version received: June 16, 2020; Accepted: June 20, 2020; Published: June 25, 2020.

DOI: 10.15376/biores.15.3.6192-6205 